\title{
REVIEW
}

\section{My approach to atypical melanocytic lesions}

\author{
K S Culpepper, S R Granter, P H McKee
}

J Clin Pathol 2004;57:1121-1131. doi: 10.1136/icp.2003.008516

Histological assessment of melanocytic naevi constitutes a substantial proportion of a dermatopathologist's daily workload. Although they may be excised for cosmetic reasons, most lesions encountered are clinically atypical and are biopsied or excised to exclude melanoma. Although dysplastic naevi are most often encountered, cytological atypia may be a feature of several other melanocytic lesions, including genital type naevi, acral naevi, recurrent naevi, and neonatal or childhood naevi. With greater emphasis being given to cosmetic results, and because of an ever increasing workload, several "quicker and less traumatising" techniques have been introduced in the treatment and diagnosis of atypical naevi including punch, shave, and scoop shave biopsies. A major limitation to all of these alternatives is that often only part of the lesion is available for histological assessment and therefore all too frequently the pathologist's report includes a recommendation for complete excision so that the residual lesion can be studied. Complete or large excision of all clinically atypical naevi permits histological assessment of the entire lesion, and in most cases spares the patient the need for further surgical intervention.
M elanocytic pathology is one of the most difficult areas in surgical pathology. The challenges fall into two broad categories, namely: the recognition of rare but characteristic entities and the much more common problem of where to place an unusual lesion on the spectrum of melanocytic lesions. A large number of melanocytic lesions fall into a borderline area that can unnerve the most experienced of pathologists. These common and vexing diagnostic problems are the subject of this review.

They include:

- mitotic activity in seemingly banal naevi

- clonal naevus

- melanoma arising in a naevus and naevoid melanoma

- Spitz naevus

- dysplastic naevus

- atypical genital naevus

- atypical acral naevus

- neonatal naevus

- melanocytic proliferations with pagetoid spread.

\section{Mitotically active naevi}

Both the general pathologist and the dermatopathologist encounter common acquired intradermal and compound naevi daily. In general, such naevi are usually mitotically inactive. However, on occasion, particularly after an especially enthusiastic search, a mitotic figure is discovered. The problem is then how to deal with it. Should one ignore it, search for more, or rush for immunohistochemistry? It should not be surprising to find an occasional mitotic figure in a compound naevus that is growing.

There are four main considerations:

- The mitosis is sporadic and incidental in an otherwise benign naevus and therefore has no clinical impact.

- The mitosis indicates an underlying "clonal" component.

- The mitosis is present in the setting of a melanoma arising in a common acquired naevus.

- The lesion itself is a naevoid melanoma.

In general, finding a mitotic figure should prompt a search for additional mitoses and a careful evaluation of the architectural and cytomorphological features. If only one mitosis is identified and the naevus is symmetrical, matures with depth, and is devoid of pleomorphism or prominent nucleoli, it is safe to disregard the mitotic figure (fig 1). Previous trauma to a naevus may sometimes result in an occasional mitosis in the superficial dermal component (recurrent naevus).

"A large number of melanocytic lesions fall into a borderline area that can unnerve the most experienced of pathologists"

\section{Clonal naevus}

Rarely, otherwise banal naevi may contain a focal pigmented atypical epithelioid component within which very occasional mitoses may be identified. These have been termed "clonal naevi" by Ball and Golitz. ${ }^{1}$ The clinical setting is usually one in which a new dark area has arisen within a naevus. Nestled within the upper half of the naevus is a small, discrete aggregate of epithelioid cells with dusty melanin pigment that are cytologically different from the remainder of the naevus (fig 2). Melanophages within and around the aggregate are common, and contribute to the darker area appreciated clinically. There is some morphological overlap between clonal naevus and inverted type A naevus and deep penetrating naevus. The clonal naevus is distinguished from these last two 


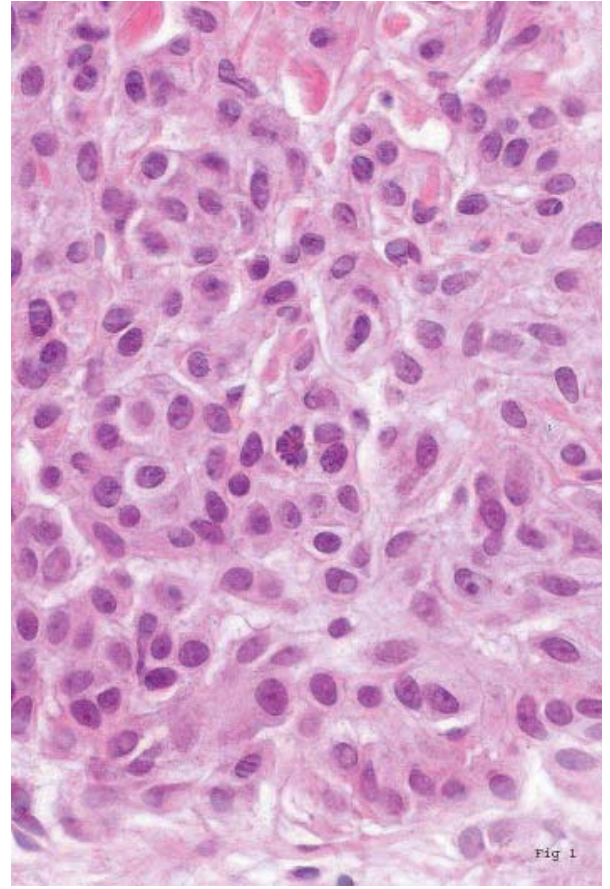

Figure 1 Banal dermal naevus showing a single mitotic figure. The nuclei are uniform.

lesions by the upper dermal location of the aggregate. Liberal examination of multiple levels may be necessary for melanoma arising in association with a naevus to be excluded confidently (see below).

\section{Melanoma arising in a naevus and naevoid melanoma} Melanoma arising in a naevus differs from a clonal naevus in several ways. Melanoma usually shows an infiltrative or, more often, an expansile growth pattern (fig 3) (intralesional transformation) compared with the well nested configuration of a clonal naevus. Melanomas efface the surrounding naevus, whereas the clonal lesion generally leaves the

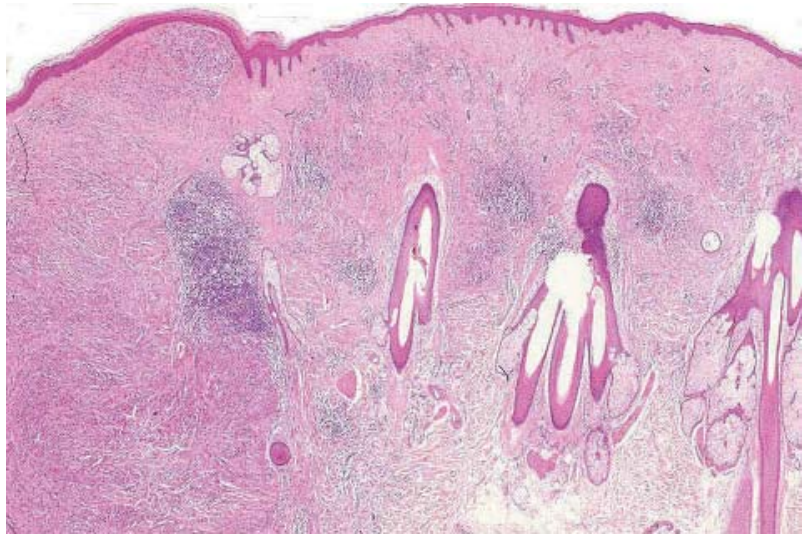

Figure 3 Melanoma (left side of field) arising in a congenital naevus from the scalp.

surrounding naevus unaffected. In general, melanoma has more numerous mitoses and greater cytological atypia (with prominent nucleoli) (fig 4), in contrast to the rare mitoses and mild cytological atypia of a clonal naevus.

In general, common naevi are diagnosable at low power; however, it is important to exclude the possibility of naevoid melanoma. This is a rare variant that mimics benign naevi and is difficult to recognise; the correct diagnosis is frequently only made retrospectively, after the patient has developed a metastasis. Zembowicz et al recently reviewed the features of naevoid melanoma. ${ }^{2}$ At low power, naevoid melanoma may have a verrucous ${ }^{3}$ or nodular architecture, and exhibit other features of a common banal naevus, including circumscription and at least relative symmetry (fig 5). Naevoid melanoma lacks the prominent junctional activity and pagetoid spread usually associated with superficial spreading melanoma. Common intradermal naevus "matures" (that is, there is an overall decrease in nest size and cellular and nuclear size with depth). On cursory examination, naevoid melanoma may appear to mature with depth, yet closer inspection reveals that the cells at the base of the lesions are similar in size to those of the superficial
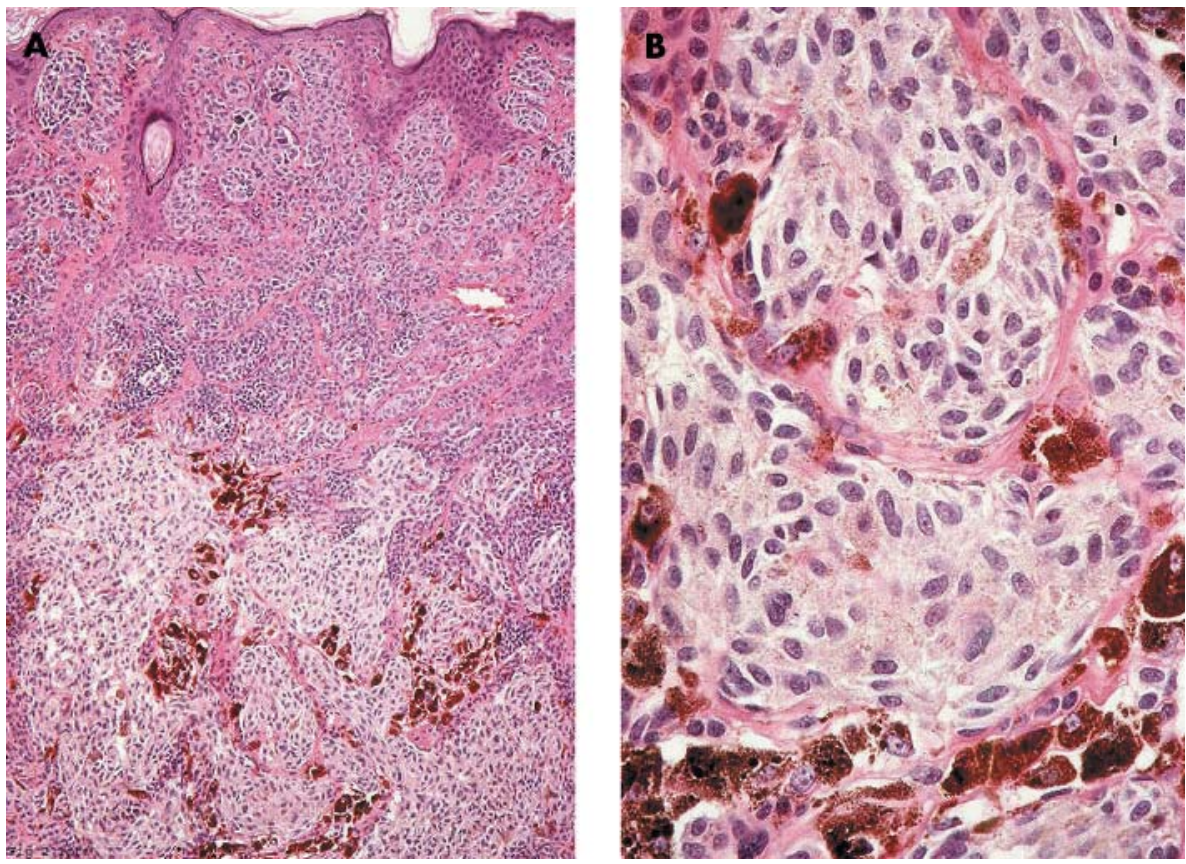

Figure 2 (A, B) Clonal naevus. Note the distinct population of pale staining naevus cells and conspicuous melanophages in the reticular dermis. 

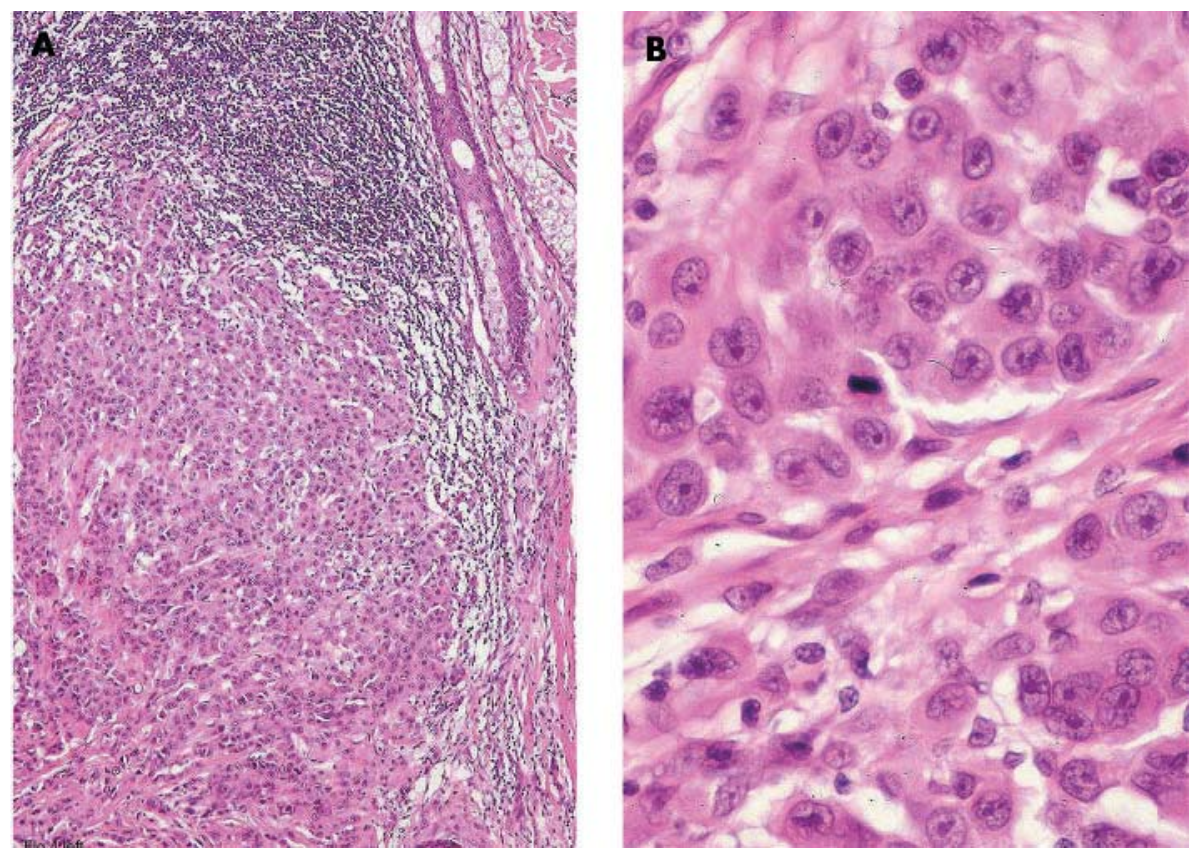

Figure 4 (A) Close up view of a circumscribed, expansile tumour nodule (left). (B) Note the large vesicular nuclei, prominent nucleoli, and mitoses.

dermal component. ${ }^{4}$ Only at higher power are the subtle distinguishing characteristics of naevoid melanoma appreciated. These include a monotonous population of small round cells with prominent nucleoli and anywhere from a few to numerous mitoses (fig 6). Other features that may be present include individual cell necrosis and atypical mitoses.

\section{"Only at higher power are the subtle distinguishing} characteristics of naevoid melanoma appreciated"

In the hands of the experienced pathologist, the histological features are usually sufficient to classify a lesion as naevoid melanoma; however, immunohistochemistry may be a valuable adjunct in difficult cases. In naevi, fewer than 5\% of cells express Ki-67 (MIB-1) and most of the reactive cells are present in the superficial dermis. ${ }^{5}$ In melanoma, MIB-1 reactive cells are more numerous and are distributed at all levels of the dermal component (fig 7). An important caveat is that lymphocytes, histiocytes, and sometimes endothelial cells may also be MIB-1 positive, and therefore cell morphology should be taken into account to determine

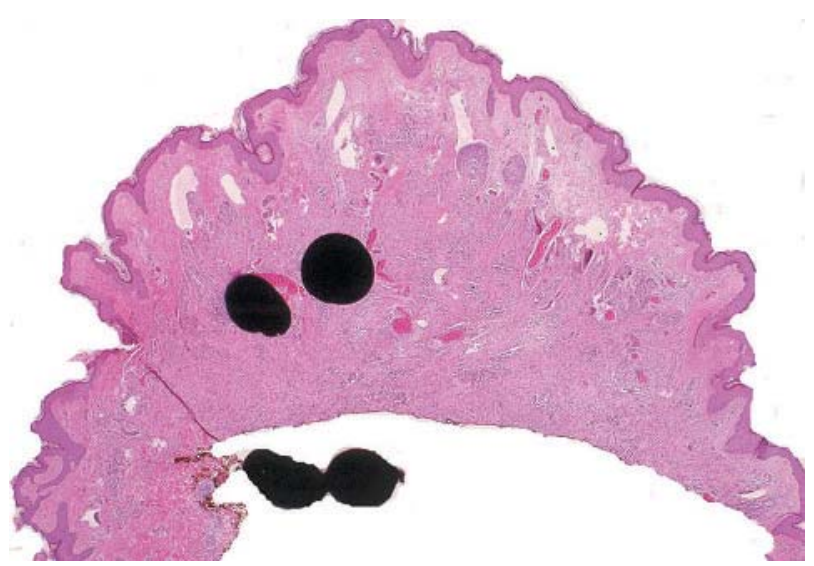

Figure 5 Naevoid melanoma from the chest of a young woman. High power views of the dotted area are shown in fig 6 . whether the immunoreactive cells are actually melanocytes. Differential staining may also be seen with $\mathrm{HMB}-45^{6}$ and cyclin $\mathrm{Dl}^{7}$; banal naevi exhibit reactivity for these immunomarkers in the superficial dermal component. HMB-45 and cyclin-1 staining in melanoma is seen throughout the dermal component (to varying degrees). It should be noted, however, that not all naevi or melanomas stain with HMB-45. In addition, it must be remembered that cyclin D1 is a nuclear antigen; therefore, cytoplasmic reactivity is not informative.

\section{Spitz naevus}

Spitz naevi are benign melanocytic lesions composed of large epithelioid and/or spindle melanocytes with abundant eosinophilic cytoplasm. Most of these lesions occur in children and can be diagnosed with confidence. Although they have been described in all age groups, great caution should be taken in rendering this diagnosis in older adults; with age there is an increasing likelihood of mistaking a melanoma for a Spitz naevus. ${ }^{8}$ Criteria for distinguishing melanoma from Spitz naevus are not always reliable, especially in older patients. Lesions reported to have features of Spitz naevus have metastasised and resulted in death. ${ }^{10}$

\section{"With age there is an increasing likelihood of mistaking a melanoma for a Spitz naevus"}

Lesions that stray from the established criteria and raise uncertainty regarding their biological potential have been called "atypical Spitz naevus" or "spitzoid tumour of uncertain biological potential". Unfortunately, some pathologists are inclined to apply these terms to histologically benign Spitz naevi for safety's sake (either the patients' safety or the pathologist perceives such terminology will lessen his/her own medical-legal risk), potentially subjecting the patient to unnecessary wide excision or sentinel node biopsy. In contrast, a lesion that some would consider frank melanoma might be "downgraded" to an intermediate lesion because of the young age of the patient. ${ }^{11}$ The knowledge that occasional patients with lesions diagnosed as Spitz naevus (even by experts) have had poor outcome further compounds diagnostic uncertainty. Despite the disadvantages of terms like "atypical Spitz naevus" and "spitzoid tumour of 

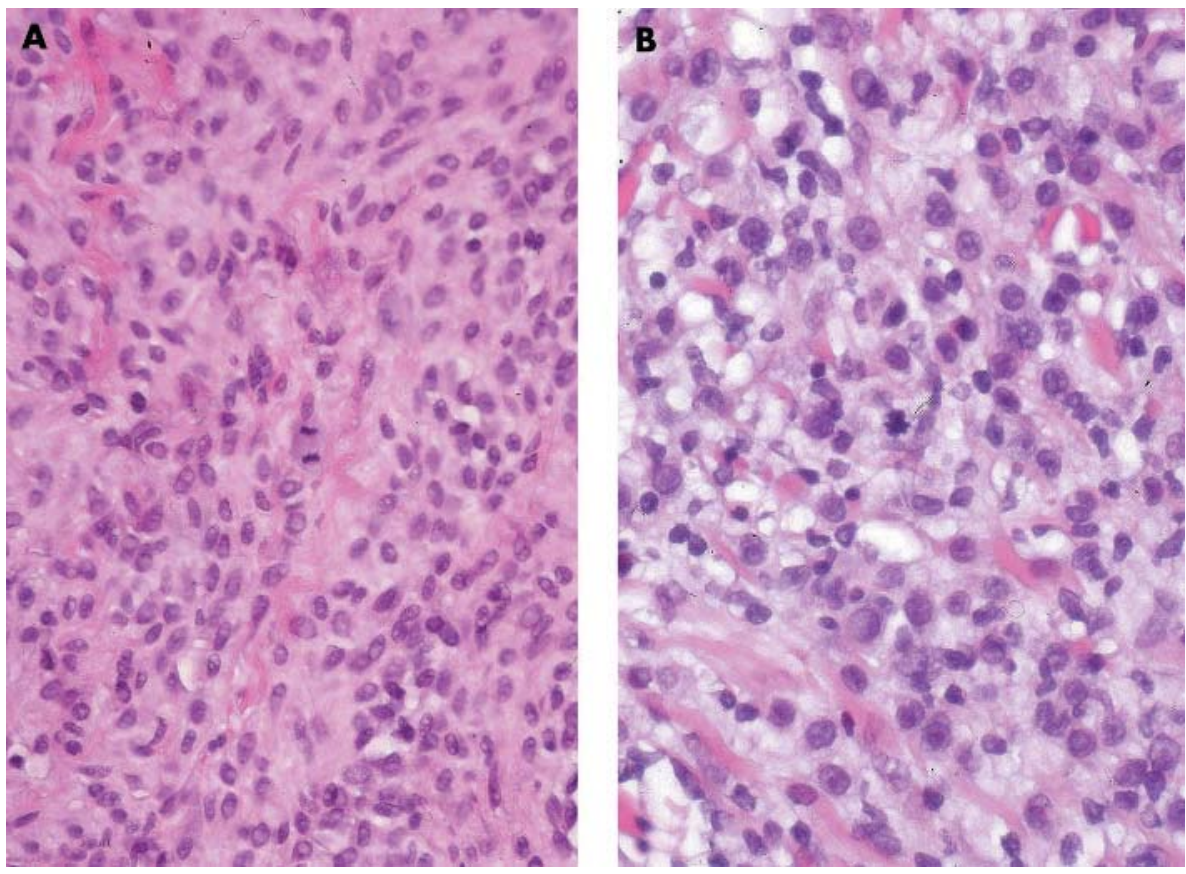

Figure 6 (A, B) The nuclei appear bland and totally banal. Note, however, the multiple mitoses.

uncertain biological potential" it must be acknowledged that not all Spitz-like tumours, particularly in adults, can be precisely classified and their use is sometimes unavoidable.

Evaluation for atypical features in Spitz-like lesions is important (table 1). Excessive mitotic activity, deep mitoses, atypical mitoses, clear lack of maturation, and a "pushing" rather than infiltrative lower border should be viewed with particular concern (figs 8 and 9). Mones has illustrated lesions in prepubescent children with a silhouette reminiscent of Spitz naevus, which, on closer scrutiny, exhibit malignant features. ${ }^{11}$ Ulceration is not an accepted feature of Spitz naevus, although true ulceration must be distinguished from traumatic ulceration, which shows parakeratosis, haemorrhage, and scale crust. Melanocytic lesions with Spitz-like features in adults-particularly when present on the back in men and on the leg of women-require careful examination to exclude melanoma.

As with naevoid melanoma, a profile of immunohistochemical stains is sometimes helpful in diagnostically challenging cases. The immunomarkers that we commonly use include HMB-45, MIB-1, cyclin D1, and p53. HMB-45

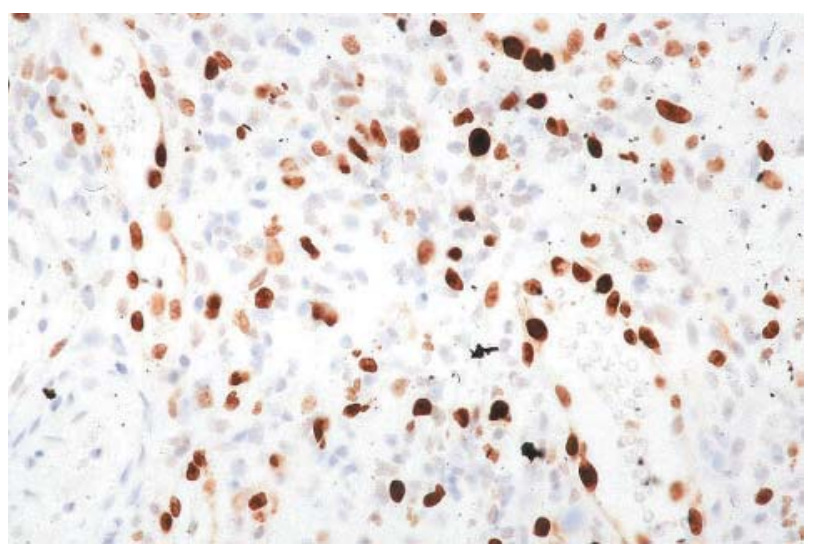

Figure 7 This MIB-1 preparation comes from the dotted areas shown in fig 5. stains most Spitz naevi, usually in a stratified manner, labelling the junctional and upper dermal components predominantly, with decreasing numbers of reactive cells with depth. ${ }^{6}$ In contrast, melanomas show patchy to diffuse staining throughout the lesion. However, as is so often the case with immunohistochemical stains, this technique is not foolproof; some Spitz naevi have been reported to stain throughout the dermal component. ${ }^{18}$

Spitz naevi demonstrate an average nuclear labelling of $4 \%$ of cells with MIB-1, whereas more than $9-25 \%$ of cells are positive in most melanomas. ${ }^{19}$ In Spitz naevi, the positive nuclei are usually concentrated in the superficial aspect, although scattered cells may be detected throughout the lesion. ${ }^{5}$ In contrast, melanoma shows an overall uneven distribution of MIB-1 staining cells, although expression is typically seen at the base of the lesion. A small percentage of both melanomas and Spitz naevi will show lower and higher proliferative activity, stressing the importance of correlating

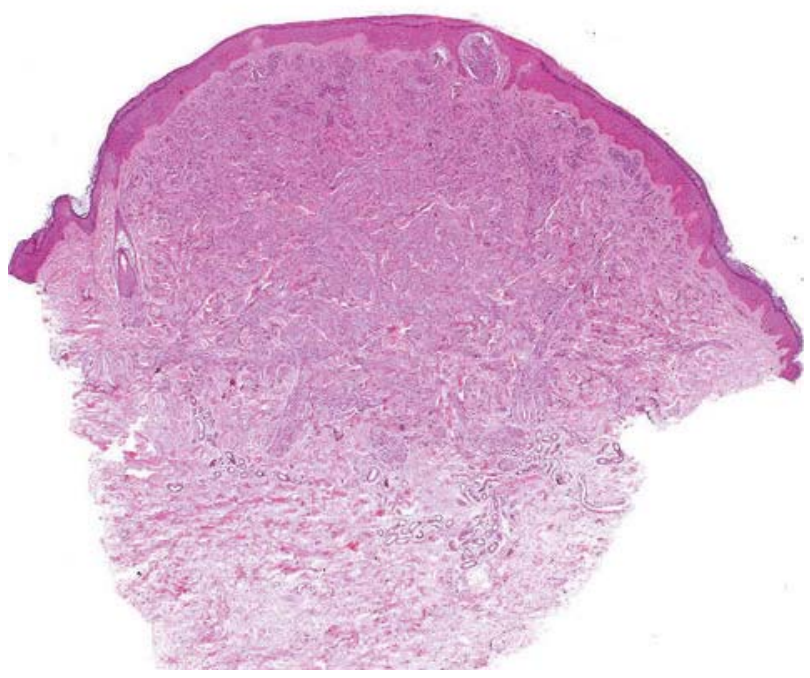

Figure 8 Atypical Spitz naevus shown at scanning magnification. 

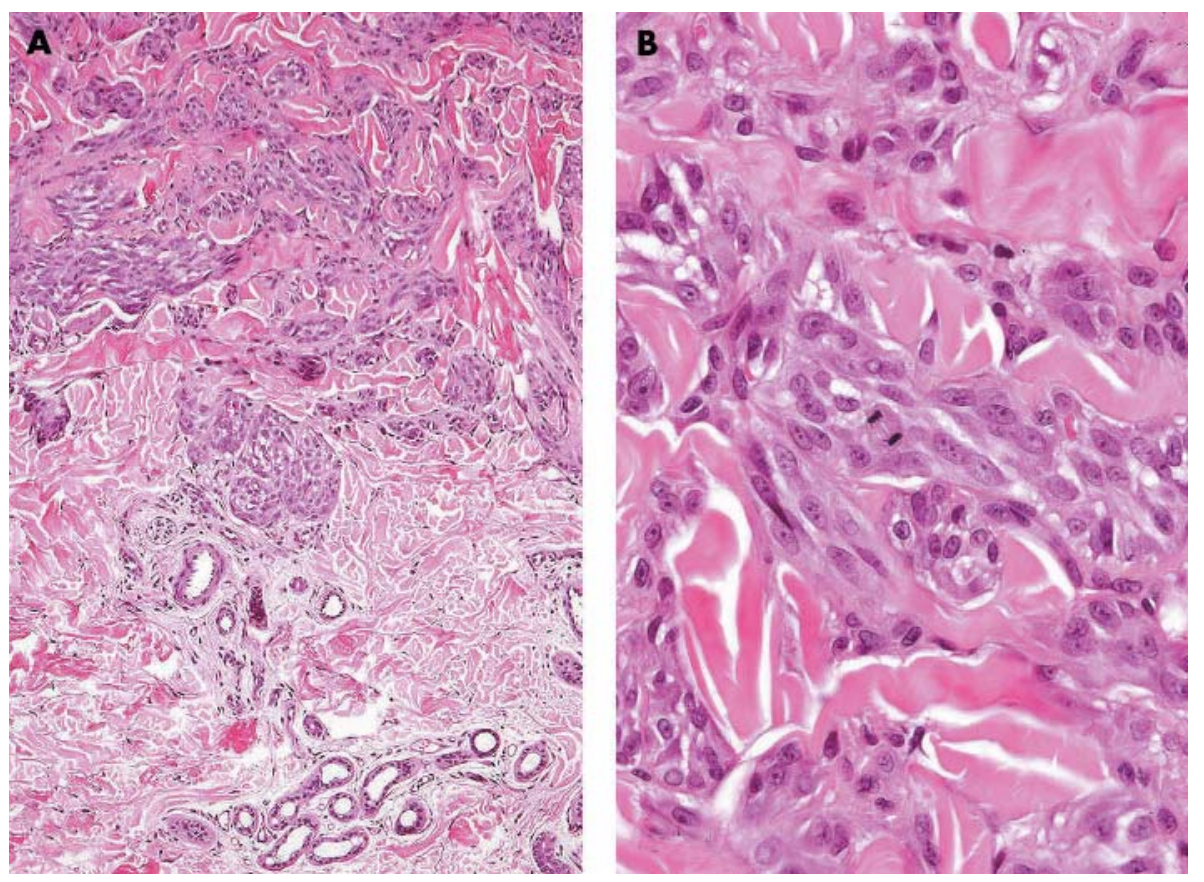

Figure 9 (A) Medium power view of fig 8 showing large nests at the deep margin. (B) Multiple mitoses were present at all levels of the naevus.

immunohistochemical results with the morphological context and clinical setting. It should be borne in mind that pronounced reactivity may be seen in the lymphocytes accompanying inflamed Spitz naevi. Therefore, care must be taken to distinguish immunoreactivity in lymphocytes from melanocytes.

Cyclin Dl is occasionally positive in the most superficial aspect of compound naevi and highly positive in melanomas. Spitz naevi may be positive for cyclin Dl; however, as with MIB-1, staining has a zonal pattern, with most of the positive cells in the superficial dermis. ${ }^{7}$ A zonal pattern of staining is not a feature of melanoma.

\section{"Advances in molecular techniques will probably provide a more definitive tool for the improved characterisation of Spitz-like lesions"}

The p53 protein is usually negative in Spitz naevi, but shows positive nuclear staining in most nodular melanomas. $^{2021}$

Table 1 Some reported atypical features observed in Spitz "naevi"

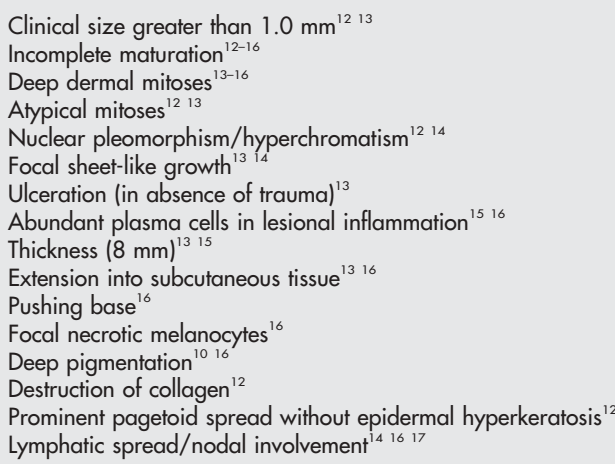

Advances in molecular techniques will probably provide a more definitive tool for the improved characterisation of Spitz-like lesions. Recently, gains of $11 \mathrm{p}$ accompanied by mutations in HRAS have been documented in some Spitz naevi but not in melanoma. ${ }^{22}{ }^{23}$ These naevi were larger and thicker, and exhibited distinct characteristics, such as larger cells with nuclear pleomorphism, deviating from prototypical Spitz naevus.

As with other melanocytic lesions, rendering a diagnosis on an incomplete biopsy-particularly one that does not allow for examination of the full thickness of the lesion for evidence of maturation and deep dermal mitoses-should be avoided. The pathologist should render a firm diagnosis only after the entire lesion has been examined.

\section{Dysplastic naevus}

Dysplastic naevi are lesions that show intermediate histological features between banal common naevi and melanoma. Several groups have demonstrated molecular differences between banal naevi, dysplastic naevi, and melanoma, supporting the view that dysplastic naevi are part of a biological spectrum that shows progression to melanoma (comprehensively reviewed by Hussein and $\mathrm{Wood}^{24}$ ). They are a marker for increased melanoma risk (the magnitude of which lies in the clinical setting-total number of moles, family history, etc) and, in some cases, are a precursor of melanoma.

The nature of the genetic defect (CDKN2A, CDK4, or neither) appears not to affect the clinical or histological appearance of dysplastic naevi or melanomas in families with the dysplastic naevus syndrome. ${ }^{25}$ In addition, there are no significant histological differences between sporadic and familial dysplastic naevi. ${ }^{26}$ Therefore, the relevance of a dysplastic naevus in a given patient rests on the clinical context.

Dysplastic naevi display a constellation of architectural and cytological features that distinguish them from other naevi and, usually, melanoma. The consensus statement issued by the National Institutes of Health in 1992 requires architectural disorder only (and not cytological atypia) to establish a diagnosis of dysplastic naevus. ${ }^{27}$ In our opinion, however, cytological atypia must also be present in accordance with the 
consensus paper of Clark et al. ${ }^{28}$ The National Institutes of Health definition is otherwise too broad and there is a considerable risk of including most naevi, dysplastic or otherwise, in the category. In fact, a minor element of architectural disorder or small focus of mild cytological atypia can be found in most naevi if one searches hard enough. But this does not necessarily warrant a diagnosis of dysplastic naevus.

Dysplastic naevi have a prominent lentiginous component, are asymmetrical, poorly circumscribed, and, if compound, have a junctional shoulder (defined as the intraepidermal component extending beyond the dermal component) (fig 10). We classify lesions as having mild, moderate, or severe cytological atypia (table 2; fig 11). Cytological atypia in a dysplastic naevus is generally random and patchy, with atypical cells punctuating a background of cells with minimal or no atypia. The presence of a monotonous population of severely atypical cells (in one region, or throughout the lesion) is worrying for melanoma.

\section{"We adhere to the standard recommendation of $5 \mathrm{~mm}$ margins in all severely atypical naevi that involve the margin" $^{\prime \prime}$}

Although grading atypia is based on cytomorphology, the architecture of the lesion contributes to the overall assessment of a naevus. ${ }^{30}$ For example, bridging (the merging of melanocytes between adjacent rete ridges) is a criterion used in the diagnosis of dysplastic naevus. Its presence or absence does not affect the cytological grade of the lesion. However, confluent bridging involving three or more adjacent rete ridges can be worrying for melanoma. Similarly, erosion of the dermoepidermal junction may be a cause for concern. Limited migration of melanocytes into the lower layers of the epidermis (pagetoid spread) is acceptable in dysplastic naevi; however, the spread of large numbers of melanocytes or extension into the upper spinous layer is not, and raises suspicion for melanoma. In these examples, architectural disorder influences the overall grade.

We do not include treatment recommendations for mildly atypical dysplastic naevi that appear to have been completely excised or are focally present at the margins. We suggest modest re-excision of dysplastic naevi with moderate atypia that extend to a margin. If the margin is substantially involved, advising a complete excision is essential, particularly in patients over the age of $30 .^{31}$ We adhere to the standard recommendation of $5 \mathrm{~mm}$ margins in all severely atypical naevi that involve the margin. We include in our

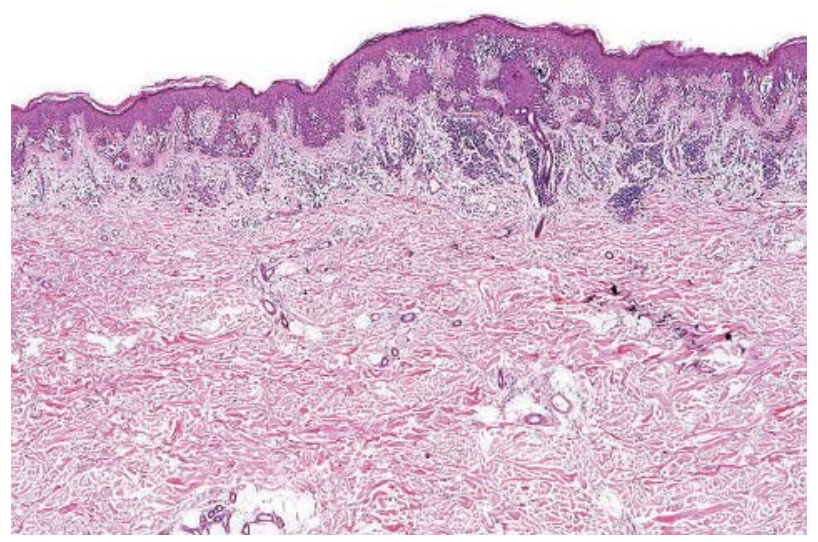

Figure 10 Dysplastic naevus showing a well developed shoulder on the left side. reports a measurement to the closest margin in severely atypical naevi that are completely excised.

Why in fact do we grade cytological atypia in dysplastic naevi? If we accept that dysplastic naevi showing different degrees of atypia form a continuum of risk of progression to melanoma, an important role is to transmit information to the clinician indicating how close to in situ melanoma a particular naevus is. In one study, Pozo et al performed a critical analysis of 15 histological variables to evaluate the reliability of grading. ${ }^{26}$ Severely atypical dysplastic naevi were reliably distinguished from those with mild or moderate atypia; however, there were no consistently reproducible features that could reliably differentiate between mild and moderate atypia. Based upon the findings, they proposed a two grade system (low and high grade) for classifying dysplastic naevi.

Is there biological evidence to support a two grade versus a three grade system? Does a naevus with moderate atypia pose more of a risk than one with mild atypia? Both may give rise to melanoma, but it is not clear that one is worse than another. There is some evidence to suggest that there are genetic distinctions between the grades. Analysing microsatellite alterations as a marker of genetic instability in genes associated with melanoma ( $1 p$ and 9p, among others), Hussein et al found microsatellite instability in both dysplastic naevi and melanoma, but not in banal naevi. ${ }^{32}$ Furthermore, there was a significant correlation between the frequency of microsatellite instability and the degree of atypia in dysplastic naevi. In particular, the prevalence of microsatellite instability was much greater in those naevi categorised as moderate and severe compared with those classified as mild, suggesting that there is a rational molecular basis for a two grade diagnostic system.

\section{"There is a significant correlation between the frequency of microsatellite instability and the degree of atypia in dysplastic naevi"}

It is important to note that not all cytologically atypical naevi are dysplastic naevi. For example, genital naevi, acral naevi, and neonatal or childhood naevi may show cytological atypia, but these are not included in the category of dysplastic naevi. Similarly, otherwise banal naevi may occasionally show foci of cytological atypia.

\section{Atypical genital-type melanocytic naevus}

Although occasional atypical naevi from the perineum are dysplastic, others fall into a category of atypical genital-type melanocytic naevus. They are most often seen in female patients-usually young women-but they are sometimes seen in children. They are characterised by a warty architecture. Large junctional nests surrounded by a well developed retraction artifact are a diagnostic clue (fig 13). They may exhibit pronounced cytological atypia (fig 14) and occasional dermal mitoses, but do not display the architecture of a dysplastic naevus. Although dermal fibrosis is often a feature of these lesions, eosinophilic and lamellar fibroplasia is lacking.

Similar lesions may be encountered at other flexural sites, including the umbilicus, groin, submammary region, and axillae-hence their alternative names of flexural naevi and milk line naevi.

The biological potential of these worrying lesions is poorly documented and their histology is often alarming. It is important therefore to take note that vulval melanoma is very much a disease of the elderly and that these atypical naevi most often occur in the young. 

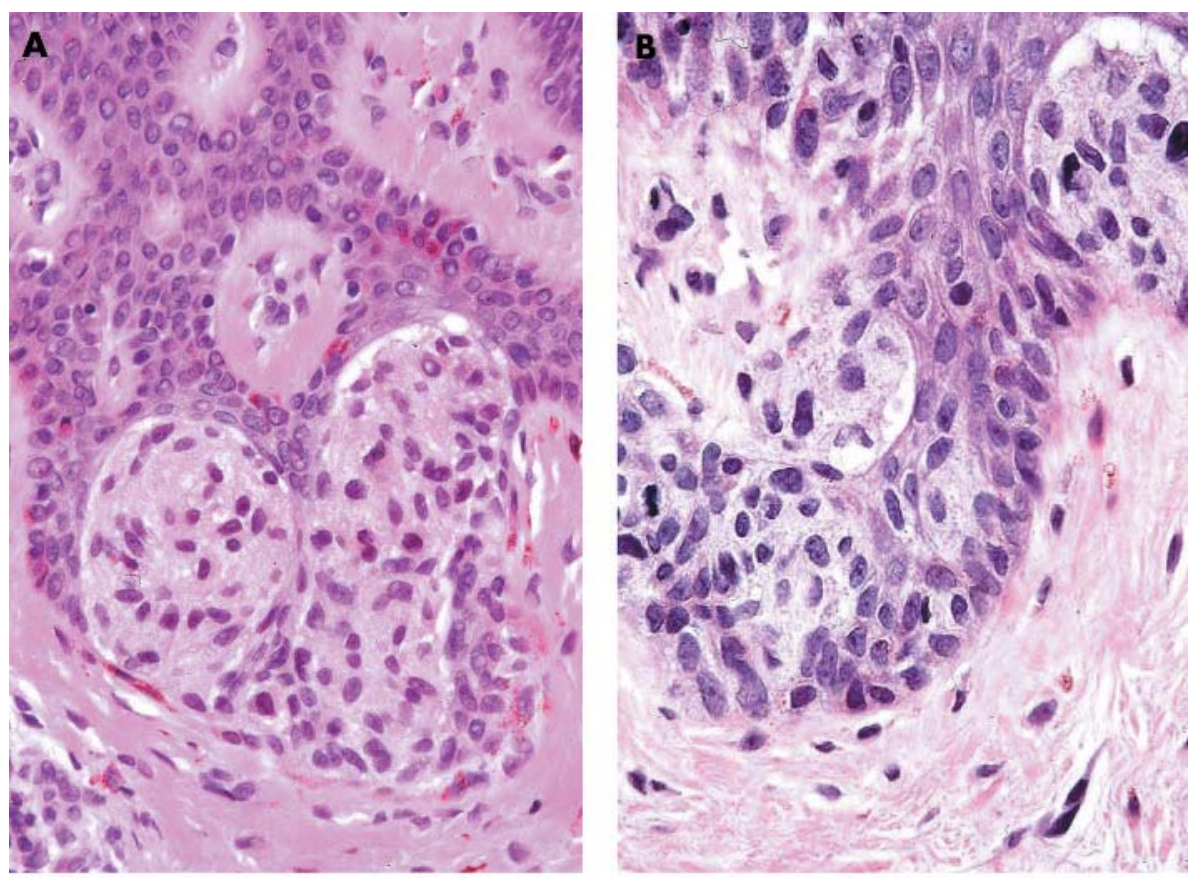

Figure 11 (A) Dusty pigment is a typical feature of a dysplastic naevus. (B) Mild cytological atypia showing enlarged hyperchromatic nuclei. (C) Moderate cytological atypia with focal upward migration in a dysplastic naevus. (D) A dysplastic naevus demonstrating severe cytological atypia and prominent nucleoli.
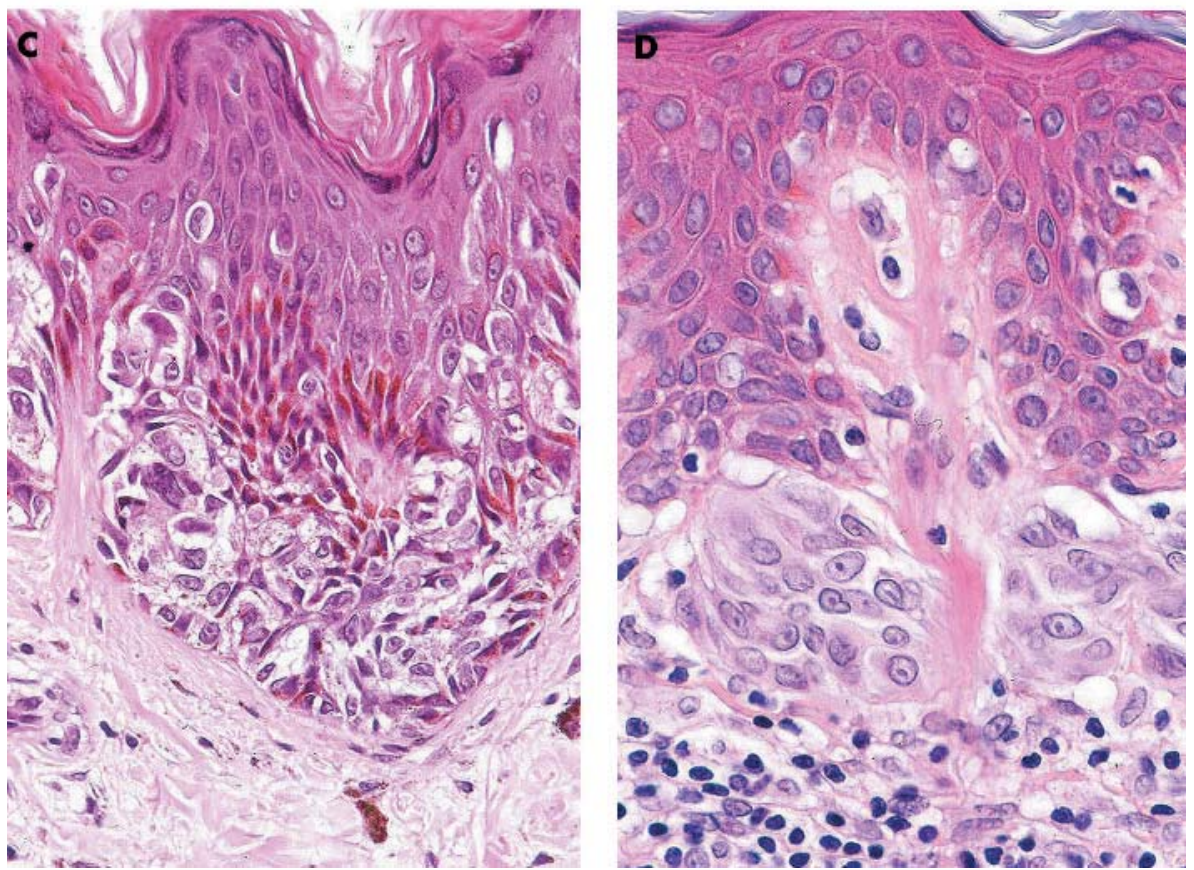

It is our policy to recommend a re-excision for lesions present at margins, as would be appropriate for a dysplastic naevus with a similar degree of atypia.

\section{Atypical acral naevi}

Atypical acral naevi are characterised by an abnormal architecture and cytological atypia and may be confused

Table 2 Grading of dysplastic naevi

\begin{tabular}{|c|c|c|c|}
\hline Parameter & Mild & Moderate & Severe \\
\hline Nuclear size & $\begin{array}{l}\text { Approximate size of keratinocyte } \\
\text { nucleus }\end{array}$ & $1-2 \times$ keratinocyte nucleus & $2 \times$ or greater than keratinocyte nucleus \\
\hline Nuclear pleomorphism & Mild & Moderate & Severe \\
\hline Chromatin & Hyperchromatic & Hyperchromatic or vesicular & Vesicular \\
\hline Nucleolus & Absent or small & Absent or small & Prominent and enlarged \\
\hline Cytoplasm & $\begin{array}{l}\text { Usually little but sometimes abundant } \\
\text { with dusty pigmentation }\end{array}$ & $\begin{array}{l}\text { Usually little but sometimes abundant } \\
\text { with dusty pigmentation }\end{array}$ & Often abundant \\
\hline
\end{tabular}




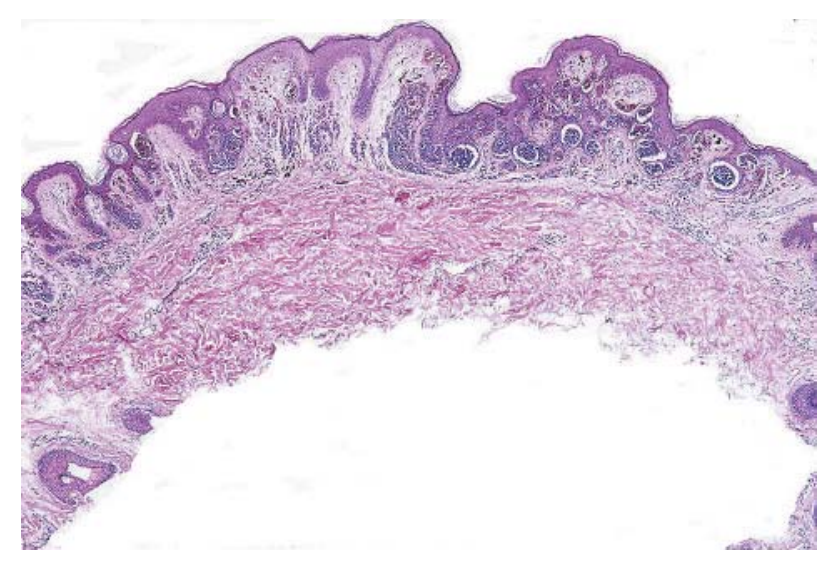

Figure 12 Atypical genital naevus showing papillomatosis and large junctional nests with a distinct retraction artifact.

with dysplastic naevi. They commonly show a junctional shoulder and nests are often situated within the suprapapillary plates, in addition to the sides of the rete, giving the lesion a disorganised appearance. The eccrine sweat ducts are also frequently involved. Cytological atypia is a common feature and, in many naevi, central pagetoid spread is present. A useful histological clue is the presence of large, oval, vertically orientated junctional nests surrounded by a retraction artifact (figs 14 and 15). The lentiginous architecture of dysplastic naevi is absent, as are lymphocytic infiltration, pigment incontinence, and dermal fibrosis.

Distinction from melanoma can be difficult in some cases, particularly in the older age groups. In general, however, the epidermis often shows irregular acanthosis in melanoma and the degree of atypia is much more pronounced. In acral atypical naevi, pagetoid spread is limited to the central part of the naevus, and dermal atypia and significant mitotic activity is not a feature. If there is any doubt, a re-excision to ensure complete removal is prudent.

\section{Neonatal naevi}

Neonatal naevi and naevi in children can also be problematical, particularly if the age of the patient is not known. Pagetoid spread and cytological atypia are common and occasional dermal mitoses may be seen. Childhood melanoma, although rare, is occasionally encountered. In our experience based on a large referral series, the diagnosis of melanoma in children is rarely challenging; these lesions usually display features similar to melanoma in adults. When compared with neonatal or childhood naevi, pleomorphism is generally more pronounced, mitoses are often conspicuous and present throughout the full thickness of the tumour, and an expansile growth pattern is a common finding. Similarly, maturation with depth is seriously impaired and necrosis may be present.

\section{Melanocytic proliferations with pagetoid spread}

The use of the term "pagetoid" to describe scatter of melanocytes throughout all levels of the epidermis originally derived from Paget's disease of the nipple, and was subsequently applied to superficial spreading melanoma. This pattern has a considerable number of non-melanocytic mimics (table 3). Each of the non-melanocytic entities can often be distinguished by morphology, but immunohistochemistry is sometimes necessary for definitive diagnosis. In addition, the presence of pagetoid cells should prompt a careful search for an adjacent dermal carcinoma or more distant tumour of origin.

Many benign melanocytic lesions may have focal upward migration of melanocytes within the epidermis, and care

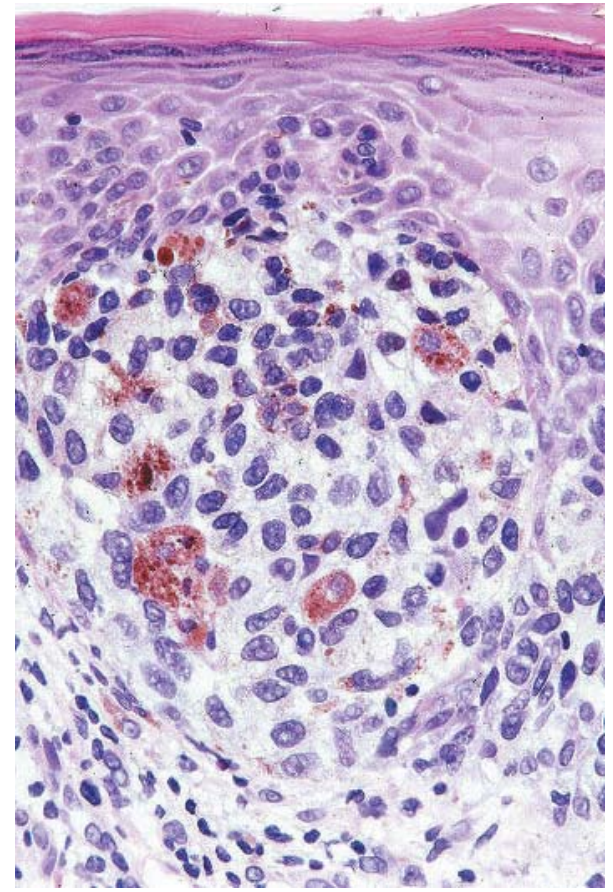

Figure 13 Atypical genital naevus showing cytological atypia.

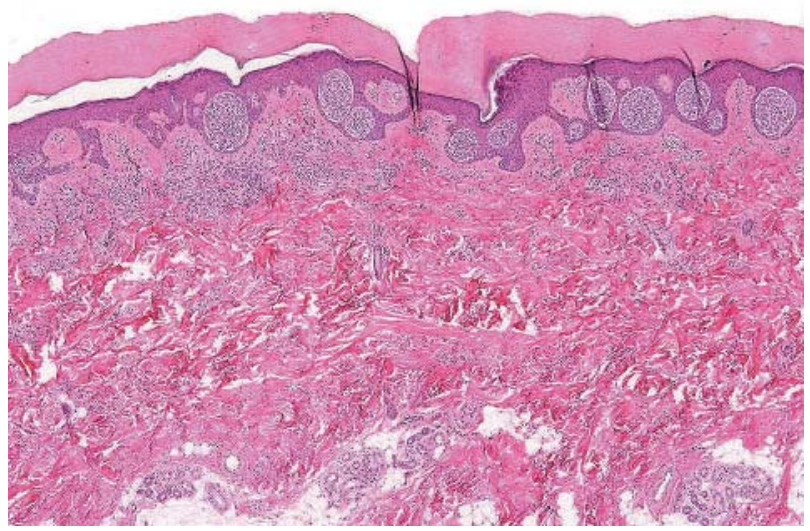

Figure 14 Atypical acral naevus showing large expansile oval junctional nests.

should be taken that they are not automatically classified as melanoma based on this feature alone. Melanocytic lesions that may exhibit suprabasal positioning of melanocytes include congenital naevi, Spitz naevi, ${ }^{39}$ acral naevi, ${ }^{40}$ genital naevi, and dysplastic naevi. ${ }^{41}$ Recurrent naevi and those naevi with recent exposure to ultraviolet irradiation exhibit reactive melanocytes with atypical cytology. ${ }^{42}$ In these last two situations, accurate and complete clinical information is of the utmost importance. In benign naevi with intraepidermal spread of melanocytes the cells are primarily localised to the basal and spinous layers in the central portion of the lesion, and are cytologically benign.

We commonly encounter junctional melanocytic proliferative lesions without an associated naevus or a significant nested component. These lesions have been termed "de novo intraepidermal epithelioid melanocytic dysplasia" by Mihm and co-workers. ${ }^{43}$ They consist of an ill defined lentiginous proliferation of epithelioid melanocytes of varying sizes and variable pagetoid spread (fig 16). They lack the cellular 

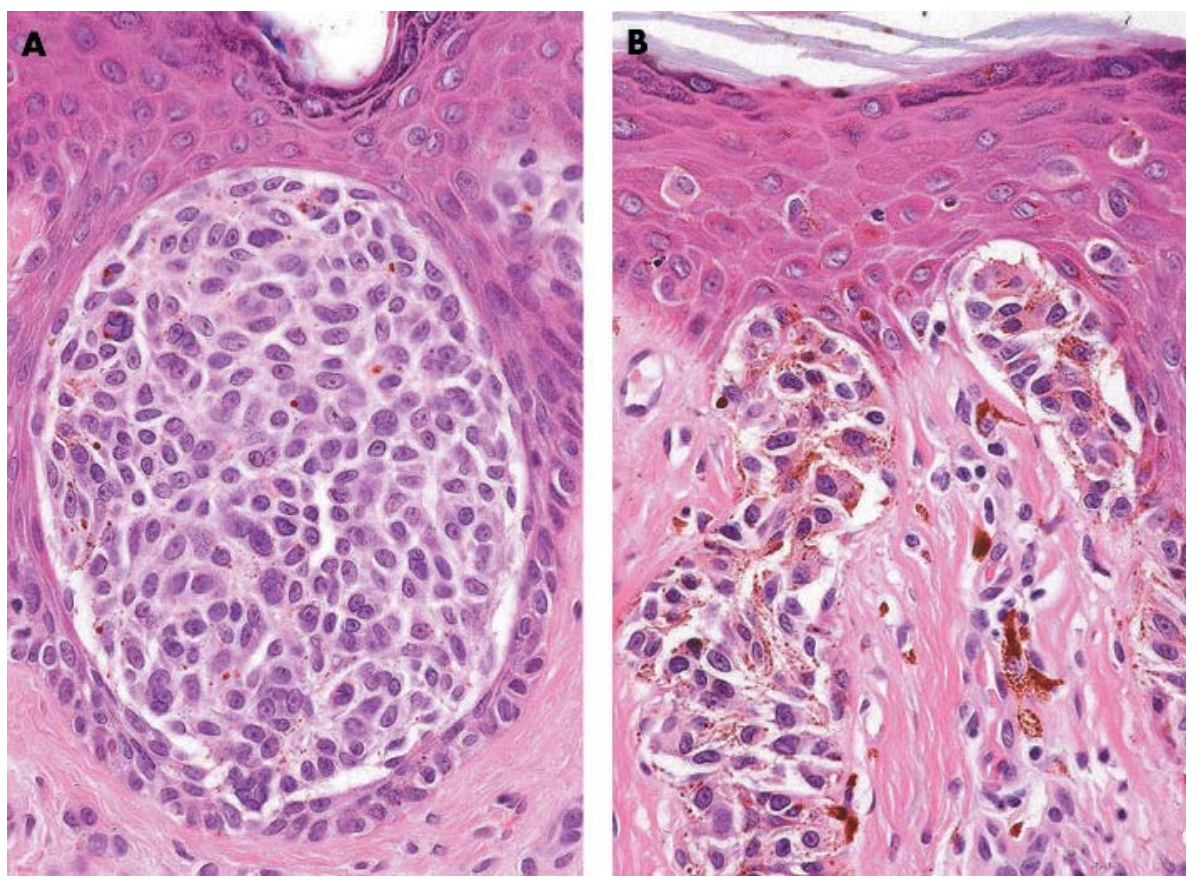

Figure 15 Atypical acral naevus. (A) High power view showing retraction artifact. (B) Note the cytological atypia and pagetoid spread.

density and atypia that would be expected from a fully evolved in situ melanoma. Nevertheless, we regard these as potential precursor lesions that may represent evolving melanoma in situ, and recommend their complete removal.

\section{Clinical considerations including treatment aspects}

Several important clinical features must be considered before rendering a diagnosis of either naevus or melanoma: duration of the lesion, previous biopsy/trauma (such as excoriation) at that site, recent sunburn/sun exposure, personal history of previous melanoma, family history of melanoma, and age of the patient. Site is also an important consideration. An atypical lesion on the back of a man or the calf of a woman should always be viewed as potential melanoma until confirmed otherwise. Unfortunately, the clinical information provided is often limited to "lesion on the leg". When confronted with an atypical lesion a phone call to the clinician is warranted to clarify the clinical context.

"An atypical lesion on the back of a man or the calf of a woman should always be viewed as potential melanoma until confirmed otherwise"

The age of the patient is of particular importance. The analysis by Geller and colleagues of the 2002 data released

Table 3 Non-melanocytic causes of pagetoid spread in the epidermis

Paget's disease
Extramammary Paget's disease
Squamous cell carcinoma in situ (Bowen's disease, bowenoid papulosis)
Pagetoid actinic keratosis ${ }^{33}$
Langerhans cell histiocytosis $^{34}$
Eccrine porocarcinoma $^{35}$
Sebaceous carcinoma
Cutaneous T cell lymphoma/pagetoid reticulosis
Intraepidermal Merkel cell carcinoma/Merkel cell carcinoma ${ }^{36}{ }^{37}$
Intraepidermal mononuclear cells/Langerhans cell microabscess
Metastatic carcinoma from a distant primary
Clear cell papulosis

from the US National Center for Health Statistics indicates that men and women age 45 and older continue to have increasing melanoma incidence and mortality ${ }^{44}$. At particular risk are men aged 65 years and older; this group had a 157\% increase in melanoma mortality and a fivefold increase in melanoma incidence from 1969 to 1999. Although the incidence of melanoma increased in both sexes in all age groups, there was a lower rate of increase in men and women aged 20-44 years, and the mortality in the same time period actually decreased in this age group.

The duration of the lesion and its stability of size, shape, and colour should be communicated to the pathologist. Most melanomas arise de novo, whereas only $25 \%$ develop in association with a pre-existing naevus. ${ }^{45} \mathrm{~A}$ new melanocytic lesion is a worrying development in a 60 year old, but is not likely to be so in a 6 year old. Recent sun exposure (suntan/ sunburn in the area of the naevus biopsied) may affect the "activity" and onset of new naevi. ${ }^{46}$

Knowledge of previous biopsy or trauma to a naevus is also important in distinguishing a recurrent naevus phenomenon

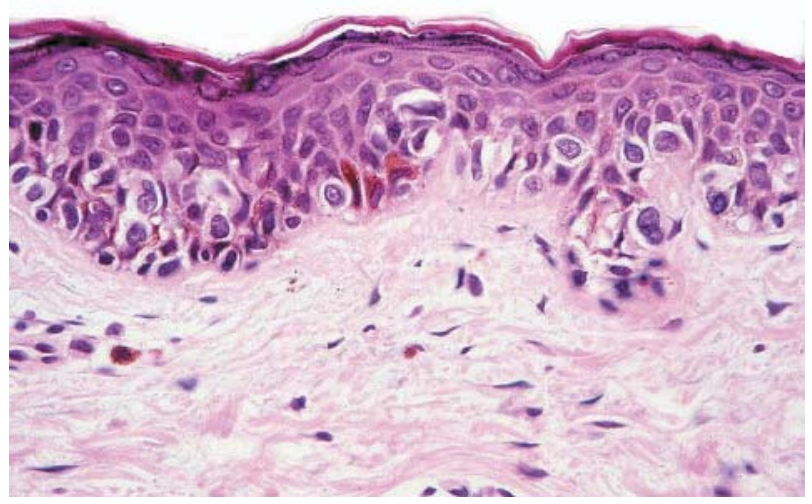

Figure 16 De novo dysplasia showing atypical epithelioid melanocytes with very occasional suprabasal forms. This is an important precursor lesion and should be fully excised. 
from melanoma. Review of the previous pathology is always helpful in challenging cases. Even minor trauma such as from excoriation may induce cytological and dermal changes that could mimic melanoma, or regression.

With greater emphasis being given to cosmetic results and because of an ever increasing workload, a number of "faster and less traumatising" techniques have been introduced in the treatment and diagnosis of atypical naevi, including punch, shave, and "scoop shave" biopsies. A major limitation to these alternatives is that often only part of the lesion is available for histological assessment, precluding definitive evaluation (fig 17). Cohen et al found residual naevus in $24.9 \%$ of re-excisions of atypical melanocytic naevi that were initially biopsied with either the shave or punch technique. ${ }^{47}$ A particularly vexing limitation with shave and punch biopsies is that they frequently contain only the central portion of the lesion and the area of interface between the melanocytic lesion and normal skin is absent. This is problematic because confident evaluation of architecture (the presence or absence of circumscription and symmetry) is not possible. Shave biopsies that sample only the superficial aspect of the lesion do not allow for evaluation of maturation.

Superficial shave biopsies frequently preclude the accurate assessment of Clark's level and tumour thickness of melanomas; this uncertainty may result in recommendation for sentinel lymph node biopsy.

Complete scalpel excision of all clinically atypical naevi permits the histological assessment of the entire lesion and for most specimens spares the patient the need for further surgical intervention. If we could persuade our clinical colleagues to excise clinically atypical naevi completely, patient care could be improved and many of our diagnostic problems would become largely academic.

The best and most practical illustration of the necessity for achieving $2 \mathrm{~mm}$ clinically clear margins is the dysplastic naevus. In compound dysplastic naevi, the junctional component often extends beyond the underlying dermal component (the "shoulder"), and trails off over several rete ridges. This corresponds to the clinical appearance of a central papule with fading edges that merge with the normal skin. To ensure complete removal, these lesions should be excised with $2 \mathrm{~mm}$ clinically clear margins to ensure that the tapering junctional component is completely excised. In the Cohen study, residual naevus was more often associated with punch than with shave biopsies, probably because the "shoulder" is more efficiently excised by shave biopsies. In addition, a recent study by Barr and colleagues documented that $35.9 \%$ of atypical naevi show variations in the degree of atypia from one area to another. ${ }^{31}$ Thus, the clinician who

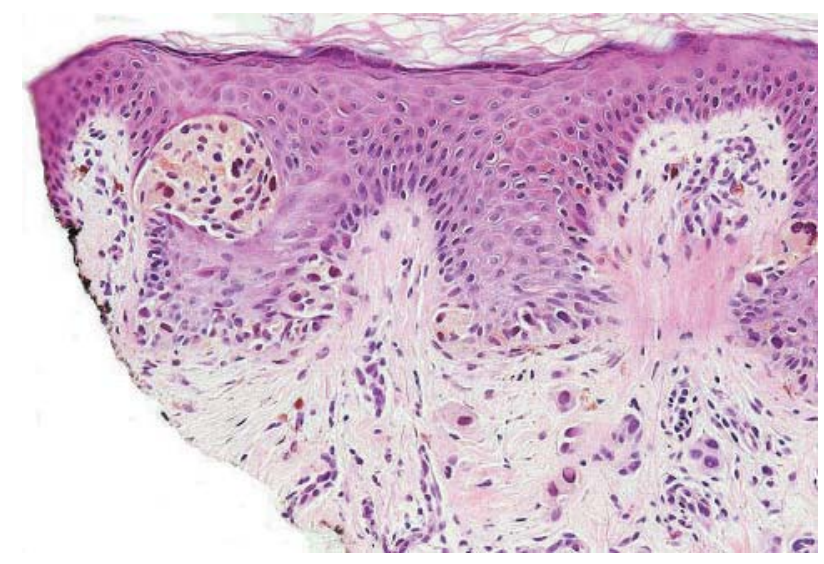

Figure 17 Dysplastic naevus showing atypia of junctional and dermal components involving an inked margin. incompletely samples a dysplastic naevus with mild atypia that extends to margins cannot be reassured that the residual lesion is not of higher grade. In the paper by Cohen et al, one lesion (in an older patient) had melanoma in the re-excision specimen. It would appear reasonable that the standard of care should be shifted to achieving $2 \mathrm{~mm}$ clear clinical margins for any naevus designated clinically atypical. Complete initial excision spares patients from a re-excision procedure and also reduces the risk of recurrence. We find that scalpel excisional biopsy is by far the best approach when dealing with clinically atypical/dysplastic naevi.

\section{"Complete scalpel excision of all clinically atypical naevi permits the histological assessment of the entire lesion and for most specimens spares the patient the need for further surgical intervention"}

Lentigo maligna is a notable exception to recommending initial complete excision because the clinical size and anatomical location often prohibit excisional biopsy. In such cases, multiple punch biopsies of different regions or, alternatively, a fusiform incisional biopsy are warranted, because a solitary biopsy may not represent the worst area of the lesion in up to $40 \%$ of cases. ${ }^{48}$

In addition to the potential risk that partial biopsy poses to the patient, the possibility of litigation is also worth bearing in mind. When we receive partial biopsies of dysplastic naevi, we are generally fairly blunt in our recommendation for a complete and adequate re-excision, and often specify the precise margin in millimetres. Some dermatologists feel that we are tying their hands unnecessarily; we take the opposite view because we are the ones who will ultimately receive the blame when things go wrong!

In conclusion, beware of atypical naevi; they may harbour a melanoma. When reporting naevi, do not ignore the one that looks slightly odd or catches your eye. It may be trying to tell you something! Don't report melanocytic lesions late in the day, stick to seborrheic keratoses and epidermoid cysts. Lastly, a second pair of eyes or even a third will sometimes save the day.

\section{Authors' affiliations}

K S Culpepper, S R Granter, P H McKee, Division of Dermatopathology, Department of Pathology, Brigham and Women's Hospital and Harvard Medical School, Boston, MA, USA

\section{REFERENCES}

1 Ball NJ, Golitz LE. Melanocytic nevi with focal atypical epithelioid cell components: a review of seventy-three cases. J Am Acad Dermatol 1994:30:724-9.

2 Zembowicz A, McCusker M, Chiarelli C, et al. Morphological analysis of nevoid melanoma: A study of 20 cases with a review of the literature. Am J Dermatopathol 2001;23:167-75.

3 Suster S, Ronnen M, Bubis JJ. Verrucous pseudonevoid melanoma. J Surg Oncol 1987;36:134-37.

4 Wong TY, Suster S, Duncan LM, et al. Nevoid melanoma: a clinicopathological study of seven cases of malignant melanoma mimicking spindle and epithelioid cell nevus and verrucous dermal nevus. Hum Pathol 1995;26:171-9.

5 Li LL, Crotty KA, McCarthy SW, et al. A zonal comparison of MIB1-Ki67 immunoreactivity in benign and malignant melanocytic lesions. Am J Dermatopathol 2000;22:489-95.

6 Bergman R, Dromi R, Trau H, et al. The pattern of HMB- 45 antibody staining in compound Spitz nevi. Am J Dermatopathol 1995;17:542-6.

7 Nagasaka T, Lai R, Medeiros $\amalg$, et al. Cyclin D1 overexpression in Spitz nevi: an immunohistochemical study. Am J Dermatopathol 1999;21:115-20.

8 Herreid PA, Shapiro PE. Age distribution of Spitz nevus vs malignant melanoma. Arch Dermatol 1996;132:352-3.

9 Barnhill RL, Argenyi ZB, From L, et al. Atypical Spitz nevi/tumors: lack of consensus for diagnosis, discrimination from melanoma, and prediction of outcome. Hum Pathol 1999;30:513-20.

10 Okun MR. Melanoma resembling spindle and epithelioid cell nevus: report of three cases. Arch Dermatol 1979;115:1416-20. 
11 Mones JM, Ackerman AB. Melanomas in prepubescent children. Am J Dermatopathol 2003;25:223-38.

12 Weedon D, Little JH. Spindle and epithelioid cell nevi in children and adults. A review of 211 cases of the Spitz nevus. Cancer 1977;40:217-25.

13 Barnhill RL, Flotte TJ, Fleischli $M$, et al. Cutaneous melanoma and atypical Spitz tumors in childhood. Cancer 1995;76:1833-45.

14 Su LD, Fullen DR, Sondak VK, et al. Sentinel lymph node biopsy for patients with problematic Spitzoid melanocytic lesions. A report on 18 patients. Cancer 2003:97:499.

15 Smith NM, Evans MJ, Pearce A, et al. Cytogenetics of an atypical Spitz nevus metastatic to a single lymph node. Pediatr Pathol Lab Med 1998; 18:115-22.

16 Smith KJ, Barrett TL, Skelton III HG, et al. Spindle cell and epithelioid cell nevi with atypia and metastasis (malignant Spitz nevus). Am J Surg Pathol 1989; 13:931-9.

17 Lohmann CM, Coit DG, Brady MS, et al. Sentinel lymph node biopsy in patients with diagnostically controversial Spitzoid melanocytic tumors. Am J Surg Pathol 2002;26:47-55.

18 Skelton HG, Smith KJ, Barrett TL, et al. HMB- 45 staining in benign and malignant melanocytic lesions. Am J Dermatopathol 1991;13:543-50.

19 Kanter-Lewensohn L, Hedblad M, Wejde J, et al. Immunohistochemical markers for distinguishing Spitz nevi from malignant melanomas. Mod Pathol 1997; 10:917-20.

20 Bergman R, Shemer A, Levy R, et al. Immunohistochemical study of p53 protein expression in Spitz nevus as compared with other melanocytic lesions. Am J Dermatopathol 1995; 17:547-50.

21 Kaleem Z, Lind AC, Humphrey PA, et al. Concurrent Ki-67 and p53 immunolabeling in cutaneous melanocytic neoplasms: an adjunct for recognition of the vertical growth phase in malignant melanomas? Mod Pathol 2000;13:217-22.

22 Bastian BC, Wesselmann, Pinkel D, et al. Molecular cytogenetic analysis of Spitz nevi shows clear differences to melanoma. J Invest Dermatol 1999; 113:1065-9.

23 Bastian BC, LeBoit PE, Pinkel D. Mutations and copy number increase of HRAS in Spitz nevi with distinctive histopathological features. Am J Pathol 2000; 157:967-72.

24 Hussein MRA, Wood GS. Molecular aspects of melanocytic dysplastic nevi. J Mol Diagn 2002:4:71-80.

25 Tucker MA, Fraser MC, Goldstein AM, et al. A natural history of melanomas and dysplastic nevi; an atlas of lesions in melanoma-prone families. Cancer 2002; $94: 3192$.

26 Pozo L, Naase M, Cerio R, et al. Critical analysis of histologic criteria for grading atypical (dysplastic) melanocytic nevi. Am J Clin Pathol 2001;115:194-204.

$27 \mathrm{NIH}$. Diagnosis and treatment of early melanoma. NIH consensus statement online, 1992 Jan 27-29 [cited 02/12/7], 10:1-26.

28 Clark WH Jr, Evans HL, Everett MA, et al. Early melanoma: histologic terms. Am J Dermatopathol 1991;13:1579-82.
29 Weinstock MA, Barnhill RL, Rhodes AR, et al. Reliability of the histopathologic diagnosis of melanocytic dysplasia. The dysplastic nevus panel [abstract]. Arch Dermatol 1997; 133:953-8.

30 Shea CR, Vollmer RT, Prieto VG. Correlating architectural disorder and cytologic atypia in Clark (dysplastic) melanocytic nevi. Hum Pathol 1999;30:500-5.

31 Barr RJ, Linden KG, Rubinstein G, et al. Analysis of heterogeneity of atypia within melanocytic nevi. Arch Dermatol 2003;139:289-92.

32 Hussein MR, Sun M, Tuthill RJ, et al. Comprehensive analysis of 112 melanocytic skin lesions demonstrates microsatellite instability in melanomas and dysplastic nevi, but not in benign nevi. J Cutan Pathol 2001;28:343-50.

33 Mai KT, Alhalouly T, Landry D, et al. Pagetoid variant of actinic keratosis with or without squamous cell carcinoma of sun-exposed skin: a lesion simulating extramammary Paget's disease. Histopathology 2002;41:331-6.

34 Hashimoto $K$, Schachner LA, Huneiti A, et al. Pagetoid self-healing Langerhans cell histocytosis in an infant. Pediatr Dermatol 1999;16:121-7.

35 Robson A, Greene J, Ansari N, et al. Eccrine porocarcinoma (malignant eccrine poroma): a clinicopathologic study of 69 cases. Am J Surg Pathol $2001: 25: 710-20$.

36 Hashimoto K, Lee MW, D'Annunzio DR, et al. Pagetoid Merkel cell carcinoma: epidermal origin of the tumor. J Cutan Pathol 1998;25:572-9.

37 Brown HA, Sawyer DM, Woo T. Intraepidermal Merkel cell carcinoma with no dermal involvement. Am J Dermatopathol 2000;22:65-9.

38 Gianotti R, Cambiaghi S, Locatelli A, et al. Clear cell papulosis (pagetoid papulosis) in a non-Asian patient. Dermatology 2001;203:260-1.

39 Busam KJ, Barnhill RL. Pagetoid Spitz nevus: intraepidermal Spitz tumor with prominent pagetoid spread. Am J Surg Pathol 1995;19:1061-7.

40 LeBoit PE. A diagnosis for maniacs. Am J Dermatopathol 2000;22:556-8.

41 Rivers JK, Cockerell CJ, McBride A, et al. Quantification of histologic features of dysplastic nevi. Am J Dermatopathol 1990;12:42-50.

42 Tronnier M, Wolff HH. UV-irradiated melanocytic nevi simulating melanoma in situ. Am J Dermatopathol 1995;17:1-6.

43 Crowson AN, Magro CM, Mihm MC. Dysplastic melanocytic nevi, de novo intraepidermal epithelioid and lentiginous melanocytic dysplasias, and nevi at specific anatomic sites. In: The melanocytic proliferations. A comprehensive text book of pigmented lesions. New York: Wiley-Liss, 2001:225-80.

44 Geller AC, Miller DR, Annas GD, et al. Melanoma incidence and mortality among US whites, 1969-1999. JAMA 2002;288:1719-20.

45 Marks R, Dorevitch AP, Mason G. Do all melanomas come from "moles"? A study of the histological association between melanocytic naevi and melanoma. Australas J Dermatol 1990;31:77-80.

46 Tucker MA, Fraser MC, Goldstein AM, et al. The risk of melanoma and other cancers in melanoma-prone families. J Invest Dermatol 1993;100:350S-5S

47 Cohen LM, Hodge SJ, Owen LG, et al. Atypical melanocytic nevi: clinical and histopathologic predictors of residual tumor at reexcision. J Am Acad Dermatol 1992;27:701-6.

48 Somach ST, Taira JW, Pitha JV, et al. Pigmented lesions in actinically damaged skin: histopathologic comparison of biopsy and excisional specimens [abstract]. Arch Dermatol 1996;132:1297-302. 